\title{
Factors Influencing Teachers' Motivation: The Case of Degga Woreda Public Primary Schools
}

\author{
Feyissa Mitiku (MA) \\ Bonga University, Department of Public Management \\ Biniam Getnet (MBA) \\ Bonga University, Department of Management
}

\begin{abstract}
The aim of this study was to investigate factors influencing teachers' motivation and their effect on performances: in the case of Degga Woreda public primary schools. Descriptive and explanatory research designs were adopted with both qualitative and quantitative research approach. The study population comprised a totaling 297 teachers from primary schools and 170 teachers were sampled for this study by using Yemane (1967). Also to identify the target respondents from total population of the study systematic random sampling techniques was used. Questionnaires, interview, and researcher observation were served as data collection instruments. The data were analyzed using descriptive (mean and standard deviation) and inferential statistics (multiple correlations and regression). The analysis was supported by the statistical software such as Statistical Package for Social Scientists 20 versions and Analysis of Moment Structures 22 versions. The key findings of doing so; reward system; job satisfaction and work situation were influence teachers' motivation. The study concluded that the reward system, job satisfaction and work situation were highly influencing teachers' motivation, and they have a major positive indirect effect on the performance of teachers. Finally, the study recommended that the ministry of education in consultation with a teacher's representative, woreda education office, heads of school, and community should include in improving the reward system, job satisfaction and work situation.
\end{abstract}

Keywords: Reward System, Work Situation, Job Satisfaction, Teachers’ Motivation

DOI: $10.7176 /$ RHSS/10-1-05

Publication date: January $31^{\text {st }} 2020$

\section{Introduction}

By Webster's New Collegiate Dictionary, a motive is something a need or desire that causes a person act. Motivation can be traced from ancient Greeks, Socrates, Plato, and Aristotle ages. The term motivation derives from the Latin word which means stimulate. According to the definition of Ajibola (1976), motivation is stimulating or inspiring peoples to attain the organizational activities as well as process of stimulating oneself to action to gratify felt need. Also, Motivation is a performance or presenting an intention that origin a person to capture some achievement (Kamalian A. , 2010).

For Adair (2004), motivation comes from within the individual and the other $50 \%$ from their environment, especially from the influence of their managers and supervisor. Employers are faced with the task of motivating employees and creating high job satisfaction among their staff. Developing programs and policies that embrace job satisfaction and serve to motivate employees take time and money. Even if the organizations have highly professionals and excess amount of employees without any motive of employees, the organization cannot attain success, the employees not achieve their goals. (Ran, 2009).

Hygiene factors are extrinsic to the job and tell the environment in which the job is performed. In a situation where there were good hygiene factors, the employee would be in satisfaction. Complex factors leading to this sense of personal growth and self actualization would show employee motivation hence maximize job satisfaction, and productivity? Motivator is intrinsic factors which determine satisfaction of employees (Herzberg, 1959).

To accomplish their goals and objectives, organizations develop strategies to compete in highly competitive markets and to increase their performance (Fisher, 2012). Nevertheless, just a few organizations consider the human capital as being their main asset, capable of leading them to success or if not managed properly can lead to failure of the organization and high staff turnover. In other word any organizations should have well manage the human resource among the four basic resources namely financial, physical, human and information resource, because the human resource is a resource which organize and operate the others left resources to achieve a certain goals of the organization (Fisher, 2012).

Teacher motivation is becoming an important issue to impart knowledge, skills and talents to learners. Mertler (1992) argued that motivated teachers are generally more productive and can influence students' achievement. Teachers' motivation is influenced by different factors, like extrinsic factors such work environment, salary and work condition. The other is by intrinsic factors such as recognition, responsibility, 
empowerment, fairness of treat and trust. Researchers often contrast intrinsic motivation with extrinsic motivation which is motivation governed by reinforcement contingencies. In the same way an intrinsically motivated teacher may perform activity in order to gain a reward like salary, promotion and training and development (Din, 2008).

Teachers' motivation has always been a central problem for leaders and managers. Unmotivated teachers are likely to spend little or no effort in their jobs, avoid the workplace as much as possible, exit the school if they are given the opportunity and produce low quality work. When teachers are motivated with work-associated factors such as salary, good leadership, work environment, promotion opportunities and trust, there is less absenteeism, turnover rate, and more committed to their jobs (Owoyele, 2017).

In Ethiopia there are many problems concerning with teachers' motivation in rural area, so this study was conducted on teachers of public primary schools, because they work in rural area in which there is many problems those make teachers' dissatisfaction like shortage of infrastructure and bad working environment.

\section{Description of the Study Area}

Descriptive of the study area was described as follows.

Figure 3. 1 LOCATION MAP OF THE STUdy AREA

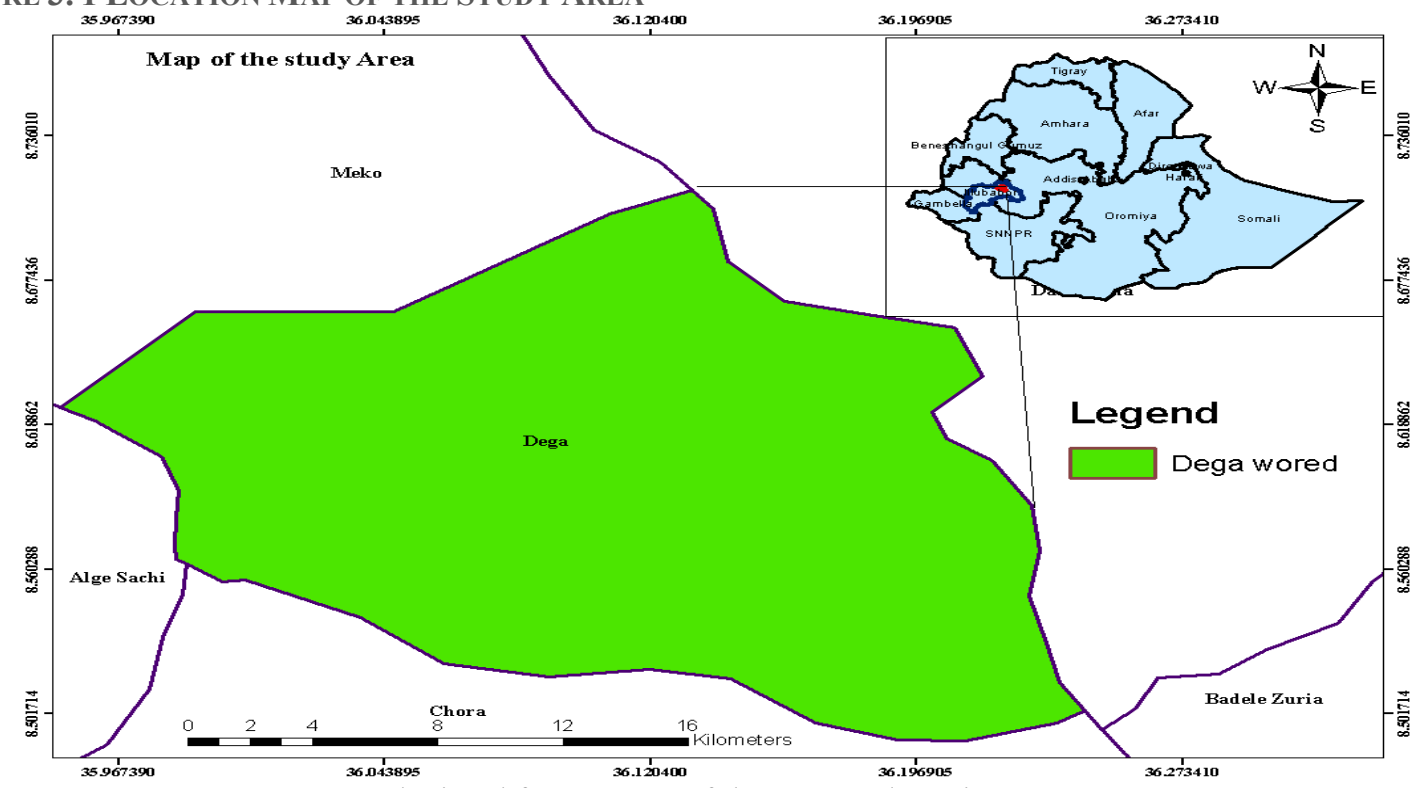

Source: depicted from a map of the country by using GIS, 2018

The above figure showed Oromia regional state, Buno Bedelle Zone, Degga woreda. This woreda was the study area that located in the western part of Ethiopia at the distance of $548 \mathrm{kms}$ from the capital city of Ethiopia, Addis Ababa and $68 \mathrm{kms}$ from Bedelle which is the capital city of Buno Bedelle zone. By the data received from the woreda cultural and tourism office, Degga woreda was established in 1872. It's bordered in the south by Chora and Bedelle woreda, in the west by Meko woreda, in the north by the Chawaka woreda and in the east by Dapho Hana woreda. The woreda has also 23 primary schools, 3 high schools, 1 preparatory school, 1 TVET College. Degga woreda has 16 rural kebeles and 1 town kebele with the total population of 54, 866 of whom 27,121 are men and 27,745 are women. The total area of land in this town is $460 \mathrm{~km}^{2}$ (Degga woreda administration office 2019).

\section{Method of Data Analysis}

This study used descriptive statistics (mean and standard deviation) and inferential statistics (multiple linear correlations and multiple linear regressions). Also this study was supported by Statistical Package for Social Scientists (SPSS) 20 version to facilitate the data analysis and Structural equation model (AMOS) 22 version, to analyze the effect estimates between independent and dependent variables (Bollen and Stine's, 1992).

Modeling the Multiple Linear Regression Y= Bo + B1X1 + B2X2 + B3X3 + e1

Where: $\mathrm{X} 1=$ reward system, $\mathrm{X} 2=$ work situation, $\mathrm{X} 3=$ job satisfaction, $\mathrm{Y}=$ teachers motivation and el $=$ error term. 


\subsection{Mean Analysis}

TABLE 4. 1 OVERALL DESCRIPTIVE SUMMERY OF INDEPENDENT AND DEPENDENT VARIABLES

\begin{tabular}{llllll}
\hline Variables & $\mathrm{N}$ & Minimum & Maximum & Mean & Std. Deviation \\
\hline Reward system & 170 & 1 & 5 & 2.18 & .681 \\
Work situation & 170 & 1 & 5 & 2.64 & .706 \\
Job satisfaction & 170 & 1 & 5 & 2.83 & .908 \\
Teachers' motivation & 170 & 1 & 5 & 2.01 & .778 \\
\hline
\end{tabular}

Source: Field data 2019 G.C

The above table explains that reward system and teachers motivation had an overall mean score of 2.18 and 2.48 this indicated that the respondents agreed on low reward system and teachers' motivation. Also as the findings in the above table shows work situation, and job satisfaction had an overall mean scores of 2.64, and 2.83 indicating that the respondents agreed on their influence on teachers' motivation respectively. This indicated that work situation, and job satisfactions were moderately rated by the respondents.

\subsection{Multiple Correlation Analysis Results}

When there are two or more than two independent variables, the analysis concerning relationship is known as multiple correlations. Correlation is the coefficient that indicates the power of linear relationship between variables. This coefficient must be statistically significant in order to be able to say that there is a relationship between variables. The correlation coefficient takes a value between -1 and $+1,+1$ indicating a perfect positive correlation and -1 indicating perfect negative correlation between two variables (Kothari., 1990).

TABLE 4. 2. CORRELATION BETWEEN INDEPENDENT VARIABLES AND TEACHERS MOTIVATION

\begin{tabular}{lllllll}
\hline Variables & 1 & 2 & 3 & 4 & 5 & 6 \\
\hline Teachers motivation & 1 & & & & & \\
Reward system & $.403^{* *}$ & 1 & & & \\
Work situation & $.350^{* *}$ & $.300^{* *}$ & 1 & & \\
Job satisfaction & $.430^{* *}$ & $.170^{*}$ & $.291^{* *}$ & 1 & \\
\hline
\end{tabular}

**. Correlation is significant at the 0.01 level (2-tailed).

*. Correlation is significant at the 0.05 level (2-tailed).

Source: Field data 2019

The above table shows that there exist a correlation between independent variables and teachers' motivation. Correlation between job satisfaction and teachers' motivation was the highest $(\mathrm{r}=0.430 ; \mathrm{p}<0.01)$ followed by reward system $(\mathrm{r}=0.403 ; \mathrm{p}<0.01)$ and work situation by $(0.350 ; \mathrm{p}<0.01)$

\subsection{Structural Equation Model Analysis}

\subsubsection{Fit Indices Test of Structural Equation Model}

Structural Equation Modeling (SEM) has become one of the techniques of choice for researchers across disciplines and increasingly is a must for researchers in the social sciences. However, the issue of how the model that best represents the data reflects underlying theory known as model fit. It is essential that researchers using the technique are comfortable with the area since assessing whether a specified model fits the data is one of the most important steps in structural equation modeling (Yuan, 2005).

TAble 4. 3 Fit Indices Test of Structural EQUation Model

\begin{tabular}{llllllll}
\hline Model & GFI & AGFI & RMR & NFI & CFI & PNFI & RMSEA \\
\hline Default Model & 1.000 & 0.999 & 0.001 & 1.000 & 1.000 & 0.048 & 0.52 \\
\hline Source
\end{tabular}

Source: Field data 2019

As table above shows that the value of GFI and AGFI are 1and 0.999 which indicated that goodness of fit laid between range from 0 to 1 and indicated great model fit between 0.9-1 (Shevlin, 1998) and (Shevlin, 2007). Another, the value of RMR is 0.001 and that indicated between 0 to 1 , not only this RMR has a good model fit approach to zero (Bentler, 1999). Also the above table indicates that the value of NFI and CFI were equal 1 which belongs 0 to 1 and indicated good model fit above 0.9 (Bentler and Bonnet, 1980). However, the goodness of fit indices of PNFI indicated that good model fit by 0.048 , thus included between 0 and 0.5 (Mulaik, 1989). Finally, the value of RMSEA showed that good model fit to some extent by 0.52 , because it was found between good model fit 0.5-1 (Maccallum, 1996). Based on the above result of model indices components, the researcher concluded that the model was fit.

\subsection{RESUlt OF REgRession Weights}

Regression analysis is adopted appropriate when the researcher has one dependent variable which is presumed to be a function of two or more variables (Kothari., 1990). Thus, the regression weight resulted from AMOS graphic was seat as below table. 
TABLE 4. 4 THE REgRESSION WEIGHTS

\begin{tabular}{lllllll}
\hline Variables & & & Estimate & S.E. & C.R. & P-value \\
\hline Teachers motivation & $<---$ & Work situation & .172 & .074 & 2.327 & .020 \\
Teachers motivation & $<---$ & Reward system & .422 & .077 & 5.464 & .000 \\
Teachers motivation & $<---$ & Job satisfaction & .212 & .062 & 3.430 & .000 \\
\hline
\end{tabular}

Source: Field data 2019G.C

The findings in the above table indicate that the regression weight for reward system and job satisfaction in the prediction of teachers' motivation are significantly different from zero at the 0.001 level (two-tailed). This indicated that both reward system and work situation have a positive regression coefficient with the teachers' motivation, because reward system is very important to fulfill the basic need of teachers. Also work situation has a great contribution, because when teacher are entertain with their environment sense of satisfaction is create in their mind.

\subsection{Effect of Independent Variables on Dependent Variable}

TABLE 4. 5 DIRECT EFFECTS OF INDEPENDENT VARIABLES ON DEPENDENT VARIABLE

\begin{tabular}{llll}
\hline & Job satisfaction & Reward system & Work situation \\
\hline Teachers motivation & .212 & .422 & .172 \\
\hline
\end{tabular}

Source: Field data 2019 G.C

Findings in the above table indicate that the direct effects of reward system, job satisfaction, and work situation on teachers' motivation are $0.422,0.212$, and 0.172 respectively. This means when reward system, job satisfaction, and work situation goes up by 1 , teachers' motivation goes up by $0.422,0.212$, and 0.172 respectively. This indicated that reward system and job satisfaction have the highest positive direct effect on teachers' motivation respectively.

From the findings of the study the researcher looked at the reward system, work situation and job satisfaction are influencing teachers' motivation in Degga woreda public primary schools respectively.

\section{Conclusions and Recommendations}

Most of the Degga woreda public primary school teachers are not satisfied with the reward system, work situation and job satisfaction. Especially, from the findings of the study it can be concluded that reward system, work situation and job satisfaction were highly influence teachers' motivation in Degga woreda public primary schools. Teachers' motivation is a function of the above factors. That is, most of them are extrinsic in nature. They are within the control of the organization management and are external obligation on the teachers. Therefore, schools can coverage on these factors to boost their teacher's levels of motivation. To handle these determinants of teachers' motivation, it is important for the managers have to know their teacher's current needs and priorities. Ultimately, satisfying the needs of the teachers would lead to motivated and high performing teachers, improved student's achievements and improved quality education.

First, the study revealed that poor reward system and un conducive work situation in Degga woreda public primary schools. Therefore, the ministry of education in consultation with teacher's representatives and Oromia education bureau should supply each school with relevant and adequate study and teaching materials also should negotiate and set up an appropriate salary scale, allowance, and fringe benefit that are in tune with the current economic environment. This will not only ensure teachers an adequate salary to meet at the basic needs but will also in many ways provide one of the important reward system for teachers to increase their performance at school

\section{REFERENCE}

Adair. (2004). On Team Building and Teamwork. India: Replica Press.

Ajibola, E. (1976). How to Motivate the Nigerian Workers. Nigerian Journal of Management.

Ajola, C. (2004). Influence of Rewards on Workers Performance in an Organization. Journal of Social Science, $8(1)$, pp.7-12.

Andrew, D. (2004). The impact of perceived leadership behaviors on satisfaction, commitment, and motivation: An expansion of the multidimensional model of leadershi. International Journal of Coaching Science, 1(1), p35-56.

Bentler, P.M. and Bonnet, D.C. (1980), "Significance Tests and Goodness of Fit in the Analysis of Covariance Structures," Psychological Bulletin, 88 (3), 588-606.

Bollen, K. A., and R. A. Stine. 1992. Bootstrapping goodness-of-fit measures in structural equation models. Sociological Methods and Research, 21: 205-229.

Chowdhury, M. S. (2007). Enhancing Motivation and Work Performance of the Salespeople: The Impact of Supervisors’ Behavior. African Journal of Business Management, 1 (9). 238-243. 
Din. (2008). A study of motivation techniques used by Heads of Institutions of Higher Education and their impact on performance of teachers, PhD Thesis, Arid Agriculture University, Rawalpindi, Pakistan.

Fisher. (2012). Facet personality and surface-level diversity as team mental model antecedents: Implications for implicit coordination. Journal of Applied Psychology, 97(4), , 825-841.

Gangai, K. N. (2014). Absenteeism at workplace: what are the factors influencing to it? International Journal of Organizational Behavior \& Management Perspectives ,3(4) , 1282-1289.

Herzberg, F. M. (1959). The motivation to work, New York: John.

Irons, J. \&. (2008). Operant Conditioning. In S. Davis, \& W. Buskist (Ed.), 21st Century psychology: a reference handbook. Thousand Oaks, CA: SAGE Publications, Inc, pp. 1-329-1-340.

Jacobi., N. (2010). Extrinsic Factors Affecting Health Worker Motivation in the Context of Task Shifting: Experiences of VCT Counselors in Ethiopia . 1-36.

Kamalian, A. R. (2010). Survey of Relationship between Organizational Justice and Empowerment (A Case Study). European Journal of Economics, Finance and Administrative Sciences, 24 , 165-171.

Kothari. (1990). Research Methodology, Methods and Techniques. Second Revised Edition. 1-303.

MacCallum, R.C., Browne, M.W., and Sugawara, H., M. (1996), "Power Analysis and Determination of Sample Size for Covariance Structure Modeling," Psychological Methods, 1 (2), 130-49.

Mertler. (1992). Value make the Company. Harvard Business Review.

Mulaik, S.A., James, L.R., Van Alstine, J., Bennet, N., Lind, S., and Stilwell, C.D. (1989), Evaluation of Goodness-of-Fit Indices for Structural Equation Models, Psychological Bulletin, 105 (3), 430-45.

Owoyele, S. (2017). Factors Influencing Employee Motivation And Its Impact On Employee Performance Keksi-Pohjanmaan Kirjapaino Oyj . 1-54.

Ran. (2009). Motivation. In C. Wankel (Ed.), Encyclopedia of business in today ${ }^{\text {ee }}$ Research in Personality, 42(4), $1109-1115$

Shevlin, M. (2007), "A time and a place for incremental fit indices," Personality and Individual Differences, 42 (5), 869-74.

Yamane T, L.(1967) .Statistics: An Introductory Analysis, $2^{\text {nd }}$ Edition. Harper and Row, New York.

Yuan, K.H. (2005), Fit Indices Versus Test Statistics, Multivariate Behavioral Research, 40 (1), 115-48. 